This item was submitted to Loughborough's Research Repository by the author.

Items in Figshare are protected by copyright, with all rights reserved, unless otherwise indicated.

\title{
Hazard assessment for typhoon-induced coastal flooding and inundation in Shanghai, China
}

PLEASE CITE THE PUBLISHED VERSION

https://doi.org/10.1029/2021jc017319

PUBLISHER

American Geophysical Union (AGU)

VERSION

AM (Accepted Manuscript)

PUBLISHER STATEMENT

An edited version of this paper was published by AGU. Copyright 2021 American Geophysical Union.

LICENCE

CC BY-NC-ND 4.0

\section{REPOSITORY RECORD}

Yin, Jie, Ning Lin, Yuhan Yang, William J Pringle, Jinkai Tan, Joannes J Westerink, and Dapeng Yu. 2021. "Hazard Assessment for Typhoon-induced Coastal Flooding and Inundation in Shanghai, China". Loughborough University. https://hdl.handle.net/2134/16629112.v1. 


\section{Hazard assessment for typhoon-induced coastal flooding and inundation in Shanghai, China}

Jie Yin ${ }^{1,2,3}$, Ning Lin ${ }^{2 *}$, Yuhan Yang ${ }^{1}$, William Pringle ${ }^{4}$, Joannes Westerink ${ }^{4}$, Dapeng Yu ${ }^{5}$

1 Key Laboratory of Geographic Information Science (Ministry of Education), East China Normal University, China

2 Department of Civil and Environmental Engineering, Princeton University, USA

3 Institute of Eco-Chongming, East China Normal University, China

4 Department of Civil Engineering and Geological Sciences, University of Notre Dame, USA

5 Department of Geography, Loughborough University, UK

Correspondence to: N.L. (email: nlin@princeton.edu)

Abstract: This paper describes an integrated statistical-hydrodynamic method to estimate typhoon-induced coastal flood and inundation hazard at the city scale. We apply the novel method to quantify storm tide and inundation hazards for a flood-prone coastal megacity-Shanghai, China. We identify two "worst-case" scenarios (extracted from over 5000 synthetic storms) that can generate unprecedentedly high flood levels in Yangtze River Estuary and Hangzhou Bay, respectively. However, we find that, under the current sea level and climate condition, mainland Shanghai is relatively safe from coastal flooding, thanks to its high-standard seawall protection. Only low-lying and poorly-protected estuarine island (Chongming) is likely to be heavily affected by flood events with long return periods. Future studies are needed to re-assess the risk for sea-level rise and climate change conditions.

Plain Language Summary: Coastal flooding associated with tropical cyclones (TCs, also called typhoons in the Northwest Pacific Basin) is often the most devastating and costliest natural hazards. Struck by a number of strong TCs in recorded history, Shanghai is highly vulnerable to coastal flooding due to its location within the Yangtze River delta, low-relief topography and high-density population. However, given the limited historical data, observation-based analysis is 
insufficient to capture the potential extreme events. In this study, we use a synthetic storm model to generate large numbers of TC events that are physically plausible but have almost never occurred in the past. Storm tide and the resultant coastal flooding induced by each TC are further simulated with a coupled circulation-inundation model. Results suggest that Shanghai may encounter extreme storm tide flooding with very low possibilities. With the protection of seawall, the city is generally immune to extensive flooding, except low-lying and poorly-protected coastal floodplain and estuarine island (Chongming).

\section{Introduction}

Tropical cyclone (TC), associated with extreme wind, rainfall and storm surge, are responsible for significant property damage and loss of life in coastal areas (Smith and Katz, 2013). Often, TC-induced storm surge together with astronomical high tide have been suggested as the primary causes of episodic flooding in low-lying coastal regions. Recent flood catastrophes illustrate that coastal cities, as the agglomeration of population and assets, are particularly vulnerable to storm tide flooding. For example, the unprecedented flooding of New Orleans due to Hurricane Katrina (2005) caused hundreds of fatalities and more than $\$ 40$ billion in economic losses, making it the worst natural disaster in U.S. history (Kates et al., 2006). Hurricane Sandy (2012) resulted in the deaths of tens of people due to drowning and at least $\$ 20$ billion in floodrelated damages in New York City (Blake et al., 2013). Coastal flooding is expected to be more frequent and devastating, owing to rapid urbanization, sea level rise and TC intensification in a warming climate (Knutson et al., 2010; Emanuel, 2013; Woodruff et al., 2013; Hallegatte et al., 2013; Lin and Shullman 2017; Marsooli et al. 2019). Hence, it is essential to quantify TC-induced flood hazards at city or regional scales.

To ensure an accurate assessment of TC-induced flood hazards for coastal cities, a large number of TC events are required particularly for addressing extreme flood hazards induced by low-probability storms. Due to the lack of sufficient 
measurements over a long period, statistical methods have been commonly used to generate large samples of synthetic TCs for a specific site (e.g. a city) of interest (Batts et al., 1980; Georgiou et al., 1983). The basic idea of these models is that probability distributions of key TC parameters (e.g. central pressure and radius of maximum wind) are fitted to the historical record, and then a Monte Carlo approach is applied to sample from these distributions. To overcome the limitation of local data, Vickery et al. $(2000,2009)$ applied the basin-wide data to develop a full track model with TC intensity along the track estimated based on storm persistent and environmental variables such as the sea surface temperature. Furthermore, Emanuel et al. (2008), Lee et al. (2018), and Jing and Lin (2020) developed more advanced track models by incorporating more environmental and oceanic variables that are essential to storm development. The advent of synthetic TC simulation has enabled probabilistic TC hazard assessment for coastal cities.

Recently, synthetic TC simulation has been increasingly used to drive storm tide simulation and assess flood hazards at the city scale. Lin et al. (2010, 2012, 2016) applied the statistical-deterministic model developed by Emanuel et al. (2008) to produce large numbers of synthetic storms for New York City (NYC), and then they used two hydrodynamic models: the Sea, Lake and Overland Surges from Hurricanes (SLOSH) model (Jelesnianski et al., 1992) and the Advanced Circulation (ADCIRC) model (Luettich et al., 1992; Westerink et al., 1994) with a high resolution mesh (up to $10 \mathrm{~m}$ around NYC) to simulate astronomical tides and storm surges induced by synthetic TCs. They estimated the probabilistic distribution of storm tides and flood heights along NYC coast and find a heavy tail for very low occurrence probability events. Furthermore, the simulated flood heights along the coast were interpolated and applied to terrain elevation for determining the flood inundation (extent and depth) and associated probabilities for NYC (Aerts et al., 2013). However, the simple nearest neighbor method used in this analysis does not consider the dynamic nature of flood routing and may cause biases in the final inundation maps. More recently, Yin et al. (2016) described a new method for coastal flood simulation by coupling ADCIRC and a simplified 2D flood inundation model (FloodMap) and applied the analysis to NYC for Hurricane Sandy. 
The coupled modeling demonstrated improved performance and provided a reliable, effective approach for simulating storm-induced flood events in coastal cities.

In this study, an integrated statistical-hydrodynamic approach is proposed by incorporating the statistical-deterministic hurricane model, ADCIRC and FloodMap in sequence, to derive probabilistic flood hazard maps and to investigate possible worst-case flood scenarios for coastal cities. The proposed approach is applied to analyze the coastal flood hazard for the city of Shanghai, which is within the Northwest Pacific Basin and is highly vulnerable to typhoon-induced coastal flooding. Typhoon Winnie (1997) caused storm tides up to nearly 7 meters above Wusong Datum, the highest in Shanghai's history. The remainder of this paper is organized as follows. Section 2 describes materials and methods, including synthetic TC dataset, storm tide simulation, flood probability analysis, and coastal inundation modeling. Section 3 presents the results and discusses the key findings. Section 4 provides the conclusions and offers suggestions for further research.

\section{Materials and Methodology}

\subsection{Synthetic TC Dataset}

To overcome the limitation of historical data, we estimate TC-induced coastal flood and inundation hazard based on large numbers of synthetic storms. We apply a synthetic TC dataset generated by a deterministic-statistical TC model (Emanuel et al. 2008). This model uses thermodynamic and kinematic statistics of the atmosphere and ocean derived from reanalysis data or climate-model estimation to produce synthetic TCs; it has been widely used to study hurricane wind, storm surge, and rainfall hazards (e.g., Emanuel 2017, Marsooli et al. 2019). Specifically, Xu et al. (2020) applied the synthetic TC model to study typhoon wind hazard for the Shanghai area. We apply the synthetic TC dataset generated in Xu et al. (2020) for the historical climate over the period 1979 2015 based on the National Centers for Environmental Prediction (NCEP) 
reanalysis (Kalnay et al. 1996). The dataset includes 5018 synthetic storms. Each synthetic storm passes within a 350-kmradius circle centered at a point near Shanghai (latitude $29.86^{\circ}$ and longitude $121.56^{\circ}$ ), and all storms pass within this circle with the maximum wind intensity (1-min wind speed at $10 \mathrm{~m}$ over sea) greater than $21 \mathrm{~m} / \mathrm{s}$ (40 knots). Each storm is characterized by 2-hourly time series of the storm parameters (i.e., time, center position, maximum wind speed, pressure deficit, and radius of maximum wind) required for storm tide modeling. The annual storm frequency associated with the storm set is about 2 storms per year.

\subsection{Storm Tide Simulation}

We use the ADvanced CIRCulation model (ADCIRC) to simulate storm tides (i.e., the total water level including storm surge and astronomical tide). ADCIRC, originally developed by Luettich et al. (1992) and Westerink et al. (1994), is a wellestablished open-source hydrodynamic model applicable to free surface circulation and transport problems. The model adopts the hydrostatic pressure assumption to numerically solve the governing equations in space and time using, respectively, the finite-element and finite-difference numerical methods. ADCIRC solves the 2-D or 3-D momentum equations to calculate velocity fields. For storm surge modeling in the coastal ocean, the 2-D depth-integrated model is usually preferred to the 3-D model because while it is computationally cheaper, it still satisfactorily captures the dominant processes that control the storm-induced water level. In the present study, we use the 2-D depth-integrated version of ADCIRC. Due to the extremely large computational resource that would require to simulate waves associated with the large number of synthetic storms, we do not apply wave simulation here and thus we neglect the effect of wave setup on the total water level. Marsooli and Lin (2018) investigated the effect of wave setup on the total water level for the US East and Gulf coasts and found that the contribution of wave setup to peak storm tides induced by the most extreme events was relatively small. Nevertheless, the effect of wave setup on the total water level for the Shanghai region need to be investigated in a future study. 
Using the mesh generation module of Surface-water Modeling System (SMS), we develop a computational mesh that extends between latitudes $21^{\circ} \mathrm{N}$ and $41^{\circ} \mathrm{N}$ and longitudes $116.5^{\circ} \mathrm{W}$ and $129.5^{\circ} \mathrm{W}$. The computational domain consists of an unstructured triangular mesh with 108,440 nodes and 209,844 elements. The mesh resolution is $<100 \mathrm{~m}$ nearshore and gradually increases to $>50 \mathrm{~km}$ in deeper waters. The bathymetry of the model is based on the bathymetry survey of Yangtze River Estuary in 2012 (Zhu and Bao, 2016) and GEBCO’s (GEneral Bathymetric Chart of the Oceans) global 30 arc sec gridded data (www.gebco.net). The vertical datum in GEBCO's global elevation model is in mean sea level. The manning's $\mathrm{n}$ value varies over the grid based on a global database for sediments on the seabed (http://portal.gplates.org/static/html/seafloor.html). The water level at the open boundaries is specified by eight major tidal constituents (K1, K2, M2, N2, O1, P1, Q1, and S2). The tidal information, including the amplitudes and phases, are obtained from the global model of ocean tides TPXO8-ATLAS with a 1/308 resolution (Egbert and Erofeeva, 2002). At closed boundaries, i.e., island and mainland shorelines, the normal flow is set to zero whereas the tangential velocity is determined based on the free-slip boundary condition.

We use analytical/parametric models to calculate the surface wind and pressure fields associated with the synthetic TCs to drive the hydrodynamic modeling. We use the parametric model of Holland (1980) to calculate the radial profile of pressure, which is related to the maximum wind speed, radius of maximum wind, and pressure deficit. We use the analytical model of Emanuel and Rotunno (2011) to calculate the wind field. The model calculates the 1 min axisymmetric wind field (associated with the storm) at the gradient level based on the storm characteristics including maximum wind speed and radius of maximum wind. For use in the ADCIRC modeling, we convert the gradient wind to the surface level (10 m above the sea surface) with a velocity reduction factor of 0.85 (Georgiou et al., 1983) and an empirical expression of inflow angles (Bretschneider, 1972). We add to the storm wind the surface environmental wind estimated as a fraction (0.55, rotated 
counter-clockwise by $20^{\circ}$ ) of the storm translation velocity, to account for the asymmetry of the wind field (Lin and Chavas, 2012). Finally, we adjust the 1-minute wind to a 10-minute average with a reduction factor of 0.893 (Powell et al., 1996). This framework of TC modeling for storm surge analysis has been implemented by various previous studies (e.g., Lin et al., 2012; Marsooli et al. 2019). Xu et al. (2020) used a similar method to estimate the wind field, and their estimated wind hazard based on the NCEP synthetic dataset compared well with wind observations in the Shanghai region.

\subsection{Flood Probability Analysis}

Statistical analysis is performed on the generated storm tides for locations/stations at 1000-m interval along the Shanghai coast. The probability of storm tide events can be estimated by extreme value models such as generalized extreme value distribution family. In this study, the Generalized Pareto Distribution (GPD) is applied to describe the limiting behavior of maximum storm tide values for all individual events using a Peaks-Over-Threshold approach (Simiu and Heckert 1996) and the maximum likelihood method (Lin et al., 2012). The GPD threshold is determined by trial to ensure that the smallest error in the distribution is obtained (Marsooli et al., 2019). Then, assuming that the storm arrival for the region is a stationary Poisson process, the return period $T$ of peak storm tide $H$ exceeding a storm tide threshold value $h$ is $T=\frac{1}{F_{r}(1-P\{H \leq h\})}$

where $P\{H \leq h\}$ is the cumulative density function (CDF) of peak storm tide and $F_{r}$ is the annual storm frequency.

\subsection{Inland Inundation Modeling}

A well-established 2D hydraulic model (FloodMap-Inertial, Yu and Lane 2011) is utilized to derive coastal flood inundation for each scenario. The model, as well as its earlier diffusion-based version (FloodMap, Yu and Lane 2006a,b) have been tested and verified in a number of different environments (e.g., Tayefi et al., 2007; Lane et al., 2008; Casas et al., 2010; 
Yin et al., 2013, 2016, 2019; Yu and Coulthard, 2015). It adopts a simplified 2D solution to numerically solve the inertial form of the 2D shallow water equations by neglecting the convective acceleration term in a raster-based domain. Inland flood routing takes the same structure as the inertial algorithm of Bates et al. (2010), but with a slightly different method to calculate the time step. Rather than using a global Courant-Freidrich-Levy Condition where the time step for the next iteration is calculated based on the maximum water depth and velocity found at the last time step (e.g. Bates and De Roo, 2000), the Forward Courant-Freidrich-Levy Condition (FCFL) approach described in Yu and Lane (2011) for the diffusion-based version of FloodMap is used in the inertial model to maintain simulation stability and minimize numerical diffusion.

To apply the model for inland flood simulation, two types of data are required: floodplain topography and boundary \& initial conditions. In terms of the floodplain topography, a city-wide Digital Elevation Model (DEM) constructed from 0.5 $\mathrm{m}$ topographic contours is available (Yin et al., 2013), with a grid cell resolution of $50 \mathrm{~m}$ and a vertical accuracy of 0.1-0.2 $\mathrm{m}$. The locations and heights of sea dikes along the coast, provided by Shanghai Water Authority (SWA), are then overlaid onto the original 'bare earth' DEM. An empirically-based, uniform manning's roughness coefficient of 0.06 was set up in each simulation to represent the effect of urban features (e.g. buildings) on flood routing. For each synthetic storm, time series (every 30 minutes) of water levels at locations every $1000 \mathrm{~m}$ interval along the coast was derived from the ADCIRC model run. An interpolation procedure was developed to automatically generate spatial and temporal grids at the floodplainsea boundary, which were used as flow boundary conditions to drive the flood modeling.

\section{Results and Discussions}

\subsection{Model Validation}



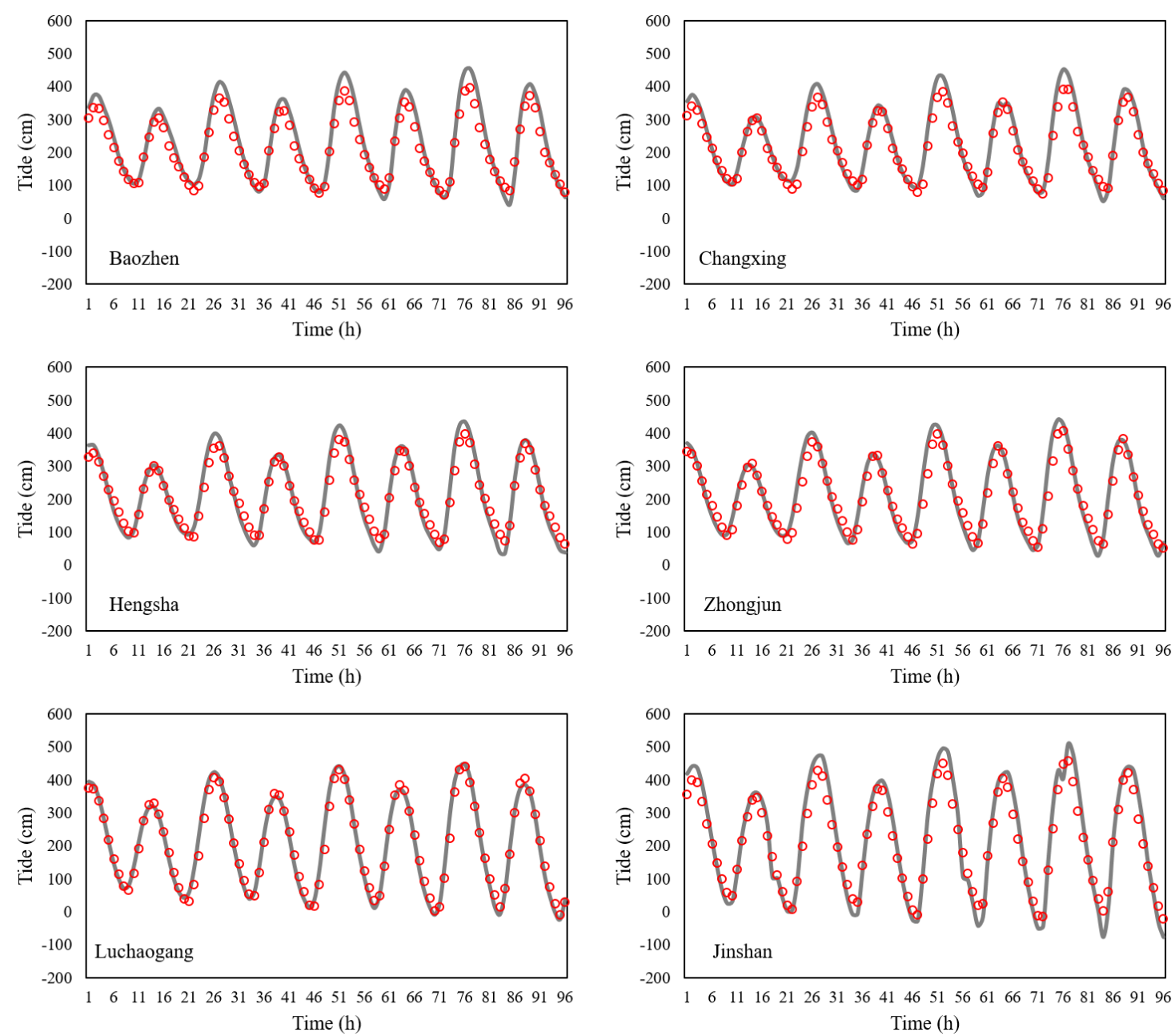

Fig.1 Time series of observed (gray lines) and modeled (red dots) tides at selected tide gauge stations around Shanghai during Typhoon Winnie (20:00:00 August 15, 1997 to 20:00:00 August 19, 1997).

As a critical TC parameter --radius of maximum wind--is not available in the historical record for Northwest Pacific Basin, it is difficult to validate the hydrodynamic modeling using historical storms. Here we evaluate the model performance in simulating astronomical tides. Fig. 1 displays the 96 -hour time series of the observed versus ADCIRC-modeled tidal water level at selected tide gauge stations (e.g. Baozhen, Changxing, Hengsha, Zhongjun, Luchaogang and Jinshan) around Shanghai during Typhoon Winnie from 20:00:00 August 15, 1997 to 20:00:00 August 19, 1997. Tides are predominantly semidiurnal with relatively small amplitude in Yangtze River Estuary and with high amplitude in Hangzhou Bay. The comparisons indicate that the simulated tides, in terms of both amplitude and phase, generally agree with the observations, suggesting that ADCIRC satisfactorily captures the dominant dynamics of major tide constituents along the Shanghai coast. 
The standard deviations (RMSEs) between the hourly tide observation and simulation at 6 gauge stations range from 0.25 $\mathrm{m}$ to $0.43 \mathrm{~m}$. It is noted that there are minor discrepancies before and after the peaks at most tide gauge stations, possibly due to the impacts of river discharges and the prominent coastal features, such as barrier islands and horn-shaped estuary.

\subsection{Probabilistic Flood Hazards}

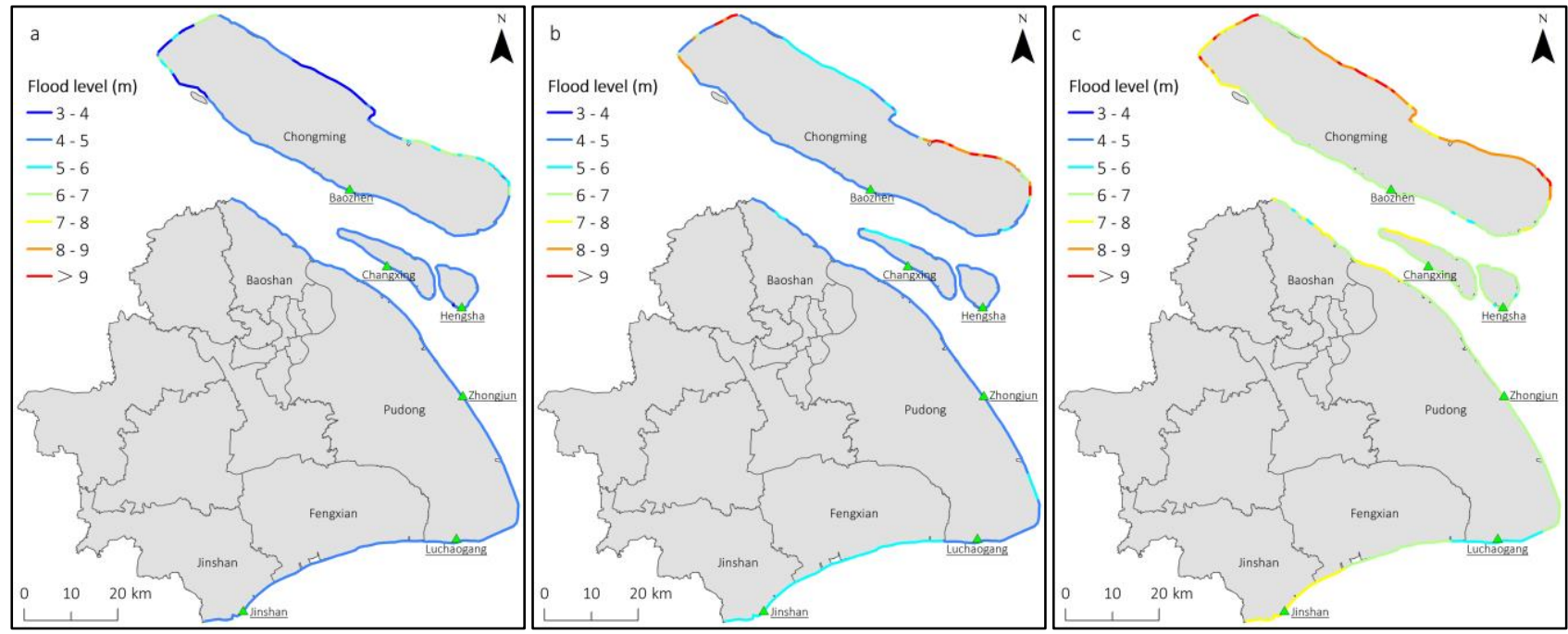

Fig.2 Estimated flood levels along the coast for 10-(a), 100-(b) and 1000-year (c) return periods under the current climate.

For each location along the Shanghai coastlines, the return periods of flood hazards (under the NCAR/NCEP current climate) are estimated through the flood probability analysis. The spatially continuous distribution of the estimated flood levels with various return periods (10-, 100- and 1000-year) along the coast is presented in Fig. 2. Results indicate that the flood level substantially increases with the increase of return period: it is between 3.77 and $6.93 \mathrm{~m}$ (with an average value of $4.37 \mathrm{~m}$ above Wusong Datum) for 10-year scenario, 4.57 and $8.48 \mathrm{~m}(5.19 \mathrm{~m})$ for 100-year scenario, and 5.88 and $12.10 \mathrm{~m}(7.03$ m) for 1000-year scenario. The highest flood return levels $(\eta)$ and the largest increases in $\eta$ over the return periods can be observed along the northern coast of the Chongming island, where the protection standard of seawall is relatively low. Compared to a previous study (Yin et al., 2020) in which flood return levels were interpolated from station-based flood probability analysis, this study presented the spatially continuous distribution of flood levels along the coast, thus providing more details and higher accuracy for flood hazard assessment. 

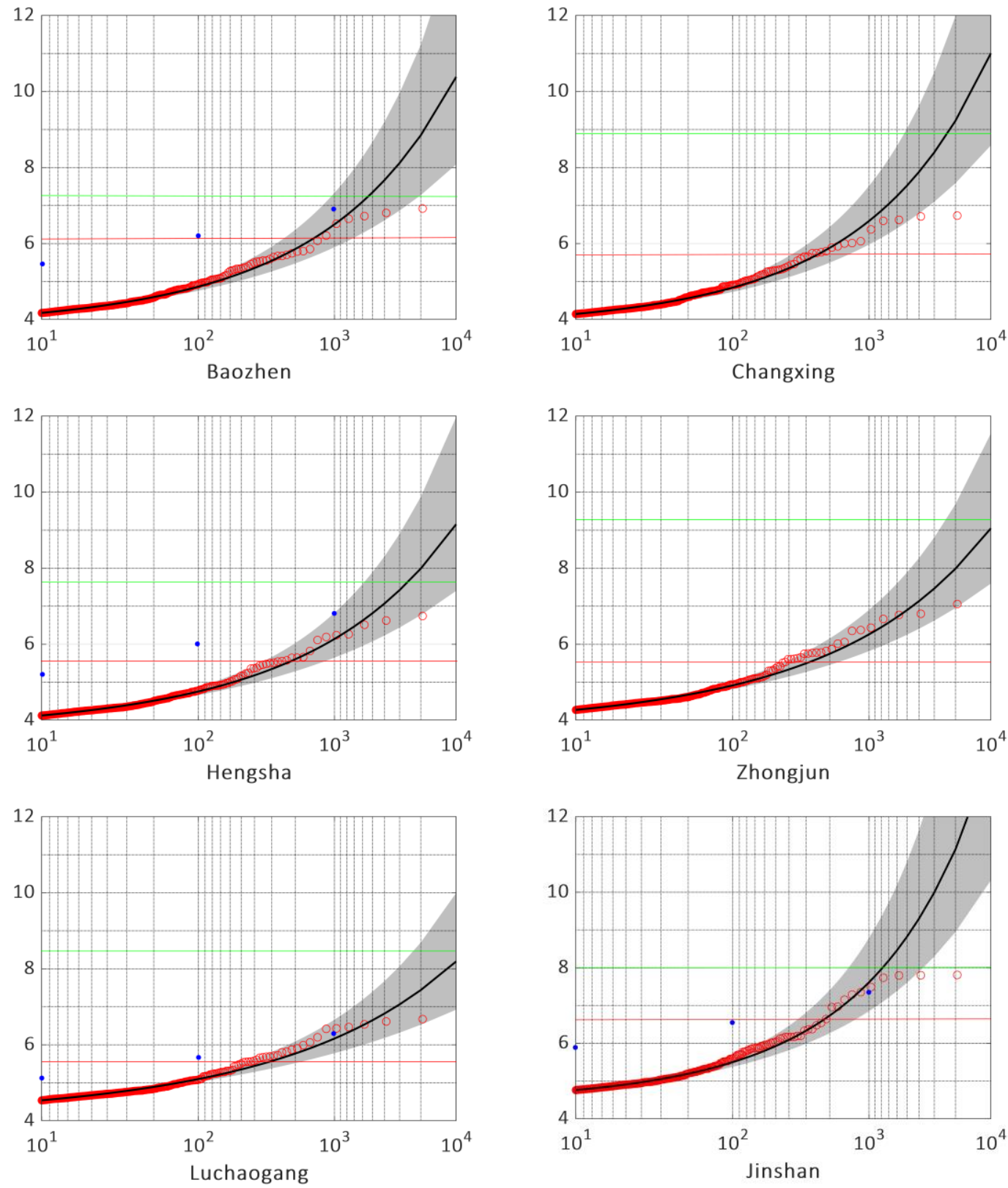

Fig.3 Estimated flood return period curves at six selected gauge stations around Shanghai for the NCAR/NCEP current climate. The $\mathrm{x}$ axis is the return period (year) and the $\mathrm{y}$ axis is the flood level (m). The shade area represents the $95 \%$ confidence interval. The green line represents the crest level of seawall at gauge stations. The red line represents the peak water level recorded at gauge stations during Typhoon Winnie. The blue dot represents the flood return period level estimated by SWA using Pearson-III distribution based on tidal gauge observations.

Fig. 3 displays the flood return level curves at selected gauge stations estimated by our analysis, compared to the estimation by SWA, respectively. Similar to that shown in Fig. 2, the predicted flood return levels vary greatly from place to place along the coast. For example, the 1000-year flood height is about $7.76 \mathrm{~m}$ at Jinshan Station but only $6.10 \mathrm{~m}$ at Luchaogang Station. Only very low-probability events (over $3000 \sim 1000$ year) will exceed the crest levels of seawall. Results also 
show a large uncertainty in flood level with a long return period (higher than 100-year). SWA, using Pearson-III distribution (based on annual maximum value of recorded still water levels), predicted significantly higher flood levels for smaller return periods (e.g. $5 \sim 6 \mathrm{~m}$ for the 10-year floods) but slightly lower heights for longer return periods at the stations (Yin et al., 2020). The flood peak water levels recorded at the gauge stations during Typhoon Winnie indicate it to be close to a 100-year event by SWA but a $800 \sim 900$ year event by our analysis. This discrepancy can be primarily attributed to the different distribution models and sample data used in the flood probability analyses. The occurrence of Typhoon Winnie may have contributed significantly to lifting the return level curves estimated based on the limited (less than 60 year) historical data. Otherwise, using limited length of historical data tends to underestimate the extremes (Lin et al., 2014; Xu et al., 2020), although SWA estimation for return periods greater than 1000 years are not available for comparison.

\subsection{Worst-case Scenarios}

The 5180 synthetic storm tide events simulated using ADCIRC are used as boundary conditions to drive inland flood modeling using FloodMap. Given the high flood wall protection, there are only a few storms that can cause inundation in Shanghai. Fig. 4 shows the spatial pattern of the storm tides and the resultant inundation footprints for three worst-case scenarios in Shanghai in the synthetic simulation under the NCAR/NCEP current climate condition (tracks shown in Fig. 4a). A large size storm (Typhoon A) moves northwestward and makes landfall in Jinshan with a high intensity. Due to the wind field's asymmetry, the largest wind forces to the right of the track push surge into Yangtze River Estuary and produce the highest storm tide (over $9 \mathrm{~m}$ above Wusong Datum) at the top end of Shanghai. Another relatively stronger northwestward-moving storm (Typhoon B) makes landfall in Chongming and induces a comparable storm tide along the northern coast of the island. A smaller-size storm (Typhoon C) which moves farther from the city also generates an extreme sea level (8.7 m above Wusong Datum) during high tide in Hangzhou Bay due to its higher intensity. The three worst-case scenarios have very low probabilities of occurrence $(>5000$ years, based on their storm tide return period at the black star 
location for each storm) and are much higher than storm tides in recorded history ( $6 \sim 7 \mathrm{~m}$ above Wusong Datum).

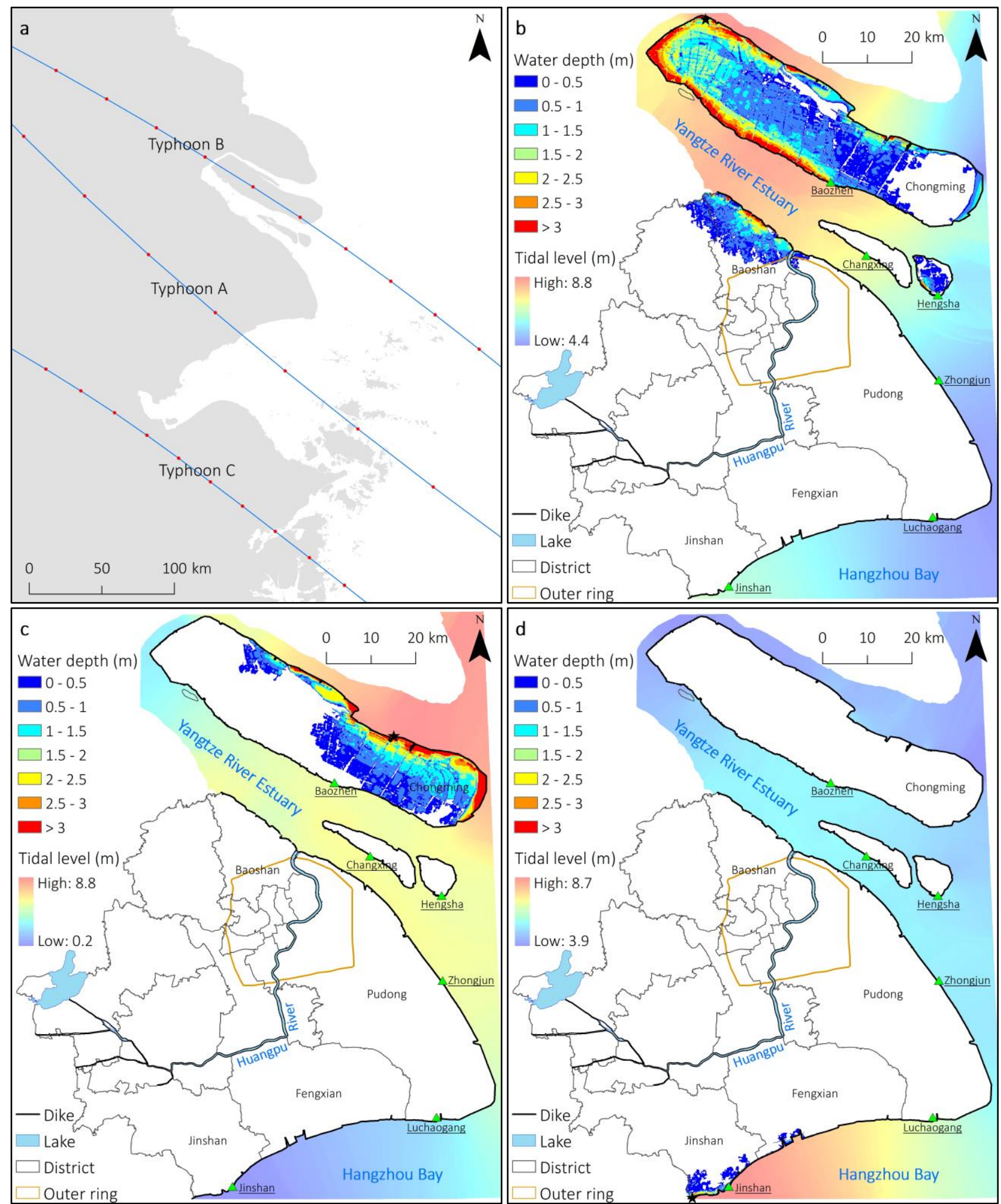

Fig.4 Three worst-case flood scenarios in Shanghai (generated by the ADCIRC and FloodMap simulations) under the NCAR/NCEP current climate. The blue curve shows the storm track (a). The black star shows the location with the maximum water level during the storm. The storm parameters when the storm makes landfall are: (b) maximum wind speed $\mathrm{V}_{\mathrm{m}}=46.9 \mathrm{~m} / \mathrm{s}$, minimum sea-level pressure $\mathrm{P}_{\mathrm{c}}=958.8 \mathrm{mb}$, radius of maximum wind $\mathrm{R}_{\mathrm{m}}=81.2 \mathrm{~km}$, and translation speed $\mathrm{U}_{\mathrm{t}}=13.4 \mathrm{~m} / \mathrm{s} ;(\mathrm{c}) \mathrm{V}_{\mathrm{m}}=51.0 \mathrm{~m} / \mathrm{s}, \mathrm{P}_{\mathrm{c}}=952.4 \mathrm{mb}, \mathrm{R}_{\mathrm{m}}=80.1 \mathrm{~km}$, and $\mathrm{U}_{\mathrm{t}}=9.0 \mathrm{~m} / \mathrm{s} ;(\mathrm{d}) \mathrm{V}_{\mathrm{m}}=52.0 \mathrm{~m} / \mathrm{s}, \mathrm{P}_{\mathrm{c}}=951.5 \mathrm{mb}, \mathrm{R}_{\mathrm{m}}=$ $63.7 \mathrm{~km}$, and $\mathrm{U}_{\mathrm{t}}=6.7 \mathrm{~m} / \mathrm{s}$. 
The synthetic events cause varying degree of coastal flood inundation in Shanghai. As expected, the highest storm tides due to Typhoon A overwhelm low-lying and poorly-protected coastal floodplains and islands in Yangtze River Estuary (Fig. 4b). When subject to Typhoon B induced coastal flooding, the inundation area covers about $564 \mathrm{~km}^{2}$ in the northeastern part of Chongming island (Fig. 4c). Particularly, the waterfront areas of western and eastern Chongming are flooded with maximum water depths higher than $3 \mathrm{~m}$. In contrast, only marginal inundations with shallow water depth (mostly lower than $0.5 \mathrm{~m}$ ) are observed in the coastal region along Hangzhou Bay (Fig. 4d). This relatively low inundation can be explained by the presence of lateral topographic confinement and the relatively high level of flood protection $(7 \sim 8 \mathrm{~m}$ above Wusong Datum). Pudong New Area and Changxing island appear to be immune to these extreme flood scenarios, because of their high standard seawalls ( $8 \sim 11 \mathrm{~m}$ above Wusong Datum) and comparatively low storm tides. Mainland Shanghai is generally safe from storm-induced flooding except a small portion of dike-protected hinterland in Baoshan. The results presented here highlight the vulnerability of seawall and island in Yangtze River Estuary, confirming the findings in Section 3.2 .

\section{Conclusions}

In this work, we develop a combined hurricane-circulation-inundation model to quantify extreme coastal flooding induced by synthetic storms under current climate in Shanghai, China. The main conclusions are summarized as follows: 1) we find that coastal inundation may only occur in low-lying and poorly-protected floodplain and island under low probability flood events; 2) we identify for the first time three "worst-case" scenarios which generate unprecedented storm tides in Yangtze River Estuary and Hangzhou Bay, respectively. The present study contributes to a better understanding of extreme coastal flooding induced by storm tide, and unlocks the potential for estimating flood hazards in a changing climate (Marsooli et al. 2019). However, since we neglect wave effects on the water level, major failure mechanisms such as seawall breach are 
not considered in the present storm flood modeling. Further work will include wave modeling and dike reliability analysis in the climatological-hydrodynamic modeling to better quantify the flood risk under both the current and future climate conditions.

\section{Acknowledgments}

This paper was supported by the National Key Research and Development Program of China (Grant no: 2018YFC1508803, 2017YFE0107400, 2017YFE0100700), the National Natural Science Foundation of China (Grant no: 41871164, 51761135024), the Social Development Project of Science and Technology Commission of Shanghai Municipality (Grant no: 19DZ1201500), the Fundamental Research Funds for the Central Universities (Grant no: 2018ECNU-QKT001, 2017ECNUKXK013), the Institute of Eco-Chongming (Grant no: ECNU-IEC-202001), and the National Science Foundation of the United States (grant EAR-1520683). We also thank Professor Kerry Emanuel (MIT) for generating the synthetic TC dataset and Professor Jianrong Zhu of ECNU for providing us with the high-resolution bathymetry data.

\section{References}

Aerts J C, Lin N, Botzen W J, Emanuel K, Moel H, 2013. Low-probability flood risk modeling for New York City, Risk Analysis, 33: $772-788$.

Bates P D, De Roo A P J, 2000. A simple raster-based model for flood inundation simulation. Journal of Hydrology, 236: 54-77.

Bates P D, Horritt M, Fewtrell T, 2010. A simple inertial formulation of the shallow water equations for efficient two-dimensional flood inundation modelling. Journal of Hydrology, 387(1-2): 33-45.

Batts M E, Cordes M R, Simiu E, 1980. Sampling errors in estimation of extreme hurricane winds. Journal of the Structural DivisionASCE, 106: 2109-2115.

Blake E S, Kimberlain T B, Berg R J, Cangialosi J P, Beven J L, 2013. Tropical cyclone report hurricane sandy (Rep. AL182012). Miami, FL: National Hurricane Center.

Bretschneider C, 1972. A non-dimensional stationary hurricane wave model. Paper presented at Offshore Technology Conference, Houston, TX (Pap. OTC 1517).

Casas A, Lane, S N, Yu D, Benito G, 2010. A method for parameterising roughness and topographic sub-grid effects in hydraulic modeling from LiDAR data. Hydrology and Earth System Sciences, 14 (8): 1567-1579.

Egbert G D, Erofeeva S Y, 2002. Efficient inverse modeling of barotropic ocean tides. Journal of Atmospheric and Oceanic Technology, 19: $183-204$

Emanuel K, Sundararajan R, Williams J, 2008. Hurricanes and global warming: Results from downscaling IPCC AR4 simulations. Bulletin of the American Meteorological Society, 89: 347-368.

Emanuel K A, Rotunno R, 2011. Self-stratification of tropical cyclone outflow. Part I: Implications for storm structure. Journal of Atmospheric Sciences, 68: 2236-2249.

Emanuel K A, 2013. Downscaling CMIP5 climate models shows increased tropical cyclone activity over the 21st century. Proceedings of the National Academy of Sciences of United States of America, 110(30): 12219-12224.

Georgiou P N, Davenport A G, Vickery P J, 1983. Design wind speeds in regions dominated by tropical cyclones. Journal of Wind Engineering and Industrial Aerodynamics, 13: 139-152.

Hallegatte S, Green C, Nicholls R J, Corfee-Morlot J, 2006. Future flood losses in major coastal cities. Nature Climate Change, 3: 802806. 
Holland G J, 1980. An analytical model of the wind and pressure profiles in hurricanes. Monthly Weather Review, 108(8): 1212-1218. Jelesnianski C P, Chen J, Shaffer W A, 1992. SLOSH: Sea, lake, and overland surges from hurricanes.

Kalnay E, Kanamitsu M, Kistler R, Collins W, Deaven D, Gandin L, Iredell M, Saha S, White G, Woollen J, Zhu Y, Leetmaa A, Reynolds R, Chelliah M, Ebisuzaki W, Higgins W, Janowiak J, Ropelewski K, Wang J, Jenne R, Dennis J, 1996. The NCEP/NCAR 40-year reanalysis project. Bulletin of American Meteorological Society, 77 (3): 437-471.

Kates R W, Colten C E, Laska S, Leatherman S P, 2006. Reconstruction of New Orleans after Hurricane Katrina: A research perspective. Proceedings of the National Academy of Sciences of United States of America, 103: 14653-14660.

Knutson T R, McBride J L, Chan J, Emanuel K, Holland G, Landsea C, Held I, Kossin J P, Srivastava A K, Sugi M, 2010. Tropical cyclones and climate change. Nature Geoscience, 3: 157-163.

Lane S N, Reid S C, Tayefi V, Yu D, Hardy R J. Reconceptualising coarse sediment delivery problems in rivers as catchment-scale and diffuse. Geomorphology, 2008, 98(34): 227-249.Lin N, Emanuel K A, Smith J A, Vanmarcke E, 2010. Risk Assessment of Hurricane Storm Surge for New York City. Journal of Geophysical Research, 115: D18121.

Lin N, Chavas D, 2012. On hurricane parametric wind and applications in storm surge modeling. Journal of Geophysical Research, 117: D09120.

Lin N, Lane P, Emanuel K A, Sullivan R M, Donnelly J P, 2014. Heightened hurricane surge risk in northwest Florida revealed from climatological-hydrodynamic modeling and paleorecord reconstruction. Journal of Geophysical Research, 119(14): 8606-8623.

Lin N, Emanuel K, Oppenheimer M, Vanmarcke E, 2012. Physically based assessment of hurricane surge threat under climate change. Nature Climate Change, 2: 462-467.

Lin N, Shullman E, 2017. Dealing with Hurricane Surge Flooding in a Changing Environment: Part I. Risk Assessment Considering Storm Climatology Change, Sea Level Rise, and Coastal Development. Stochastic Environmental Research and Risk Assessment, 31: $2379-2400$

Lin N, Kopp R E, Horton B P, Donnelly J P, 2016. Hurricane Sandy's Flood Frequency Increasing from Year 1800 to 2100. Proceedings of the National Academy of Sciences of the United States, 113 (43): 12071-12075.

Luettich R A, Westerink J J, Scheffner N W, 1992. ADCIRC: An advanced three-dimensional circulation model for shelves, coasts and estuaries. Report 1. Theory and methodology of ADCIRC-2DDI and ADCIRC-3DL (Tech. Rep. DRP-92-6). Vicksburg, MS: U.S. Army Corps of Engineers.

Marsooli R, Lin N, 2018. Numerical modeling of historical storm tides and waves and their interactions along the U.S. east and Gulf Coasts. Journal of Geophysical Research: Oceans, 123, 3844-3874.

Marsooli R, Lin N, Emanuel K, Feng K. Climate change exacerbates hurricane flood hazards along US Atlantic and Gulf Coasts in spatially varying patterns. Nature Communications, 2019, 10: 3785 .

Powell M D, Houston S H, Reinhold T A, 1996. Hurricane Andrew's landfall in South Florida. Part I: standardizing measurements for documentation of surface wind fields. Weather Forecast. 11: 304-328.

Simiu E, Heckert N A. Extreme wind distribution tails: a peak over threshold approach. Journal of Structural Engineering (ASCE), 1996 122: $539-547$.

Smith A B, Katz R W. US billion-dollar weather and climate disasters: Data sources, trends, accuracy and biases. Natural Hazards, 2013, 67: 387-410.

Tayefi V, Lane S N, Hardy R J, Yu D. A comparison of one- and two-dimensional approaches to modelling flood inundation over complex upland floodplains. Hydrological Processes, 2007, 21(23): 3190-3202.

Vickery P J, Skerjl P F, Twisdale L A, 2000. Simulation of hurricane risk in the U.S. using empirical track model. Journal of Structural Engineering, 126: 1222-1237.

Vickery P J, Wadhera D, Twisdale L A Jr, Lavelle F M, 2009. U.S. hurricane wind speed risk and uncertainty. Journal of Structural Engineering, 135: 301-320.

Westerink J J, Luettich R A, Blain C A, Scheffner N W, 1994. ADCIRC: An advanced three-dimensional circulation model for shelves, coasts and estuaries. Report 2: Users' manual for ADCIRC-2DDI (Tech. Rep. DRP-92-6). Vicksburg, MS: U.S. Army Corps of 
Engineers.

Woodruff J D, Irish J L, Camargo S J, 2013. Coastal flooding by tropical cyclones and sea-level rise. Nature, 504: 44-52.

Xu H, Lin N, Huang M, Lou W, 2020. Design tropical cyclone wind speed when considering climate change. ASCE Journal of Structural Engineering, 146(5): 04020063.

Yin J, Yu D P, Yin Z E, Wang J, Xu S Y, 2013. Modelling the combined impacts of sea-level rise and land subsidence on storm tides induced flooding of the Huangpu River in Shanghai, China. Climatic Change, 2013, 119(3): 919-932.

Yin J, Lin N, Yu D. Coupled modeling of storm surge and coastal inundation: a case study in New York City during Hurricane Sandy. Water Resources Research, 2016, 52: 8685-8699.

Yin J, Zhao Q, Yu D, Lin N, Kubanek J, Ma G, Liu M, Pepe A. Long-term flood-hazard modeling for coastal areas using InSAR measurements and a hydrodynamic model: the case study of Lingang New City, Shanghai. Journal of Hydrology, 2019, 571 : 593604.

Yin J, Jonkman S, Lin N, Yu D, Aerts J, Wilby R, Pan M, Wood E, Bricker J, Ke Q, Zeng Z, Zhao Q, Ge J, Wang J. Flood risks in sinking delta cities: time for a re-evaluation? Earth's Future, 2020, doi: 10.1029/2020EF001614.

Yu D, Lane S N, 2006a. Urban fluvial flood modelling using a two-dimensional diffusion wave treatment, part 1: mesh resolution effects. Hydrological Processes, 20: 1541-1565.

Yu D, Lane S N, 2006b. Urban fluvial flood modelling using a two-dimensional diffusion wave treatment, part 2: development of a sub grid-scale treatment. Hydrological Processes, 20: 1567-1583.

Yu D, Lane S N, 2011. Interaction between subgrid-scale resolution, feature representation and grid-scale resolution in flood inundation modelling. Hydrological Processes, 25: 36-53.

Yu D P, Coulthard T J, 2015. Evaluating the importance of catchment hydrological parameters for urban surface water flood modelling using a simple hydro-inundation model. Journal of Hydrology, 524: 385-400.

Zhu J, Bao D, 2016. The effects of river regime changes in the Changjiang Estuary on hydrodynamics and salinity intrusion in the past 60 years I. River regime changes. Haiyang Xuebao, 2016, 38(12): 11-22. 